\title{
Using Skin Bioengineering to Highlight How Weight and Diabetes Mellitus Modify the Skin in the Lower Limbs of Super-Obese Patients
}

This article was published in the following Dove Press journal: Diabetes, Metabolic Syndrome and Obesity: Targets and Therapy

\author{
Elisabetta lacopi $\mathbb{D}^{\prime}$ \\ Nicola Riitano ${ }^{1,2}$ \\ Valentina Dini ${ }^{2}$ \\ Rossana Berta $\mathbb{( D}^{3}$ \\ Letizia Pieruzzi ${ }^{1}$ \\ Agata Janowska ${ }^{2}$ \\ Marco Anselmino 3 \\ Alberto Piaggesi' \\ Marco Romanelli (iD) ${ }^{2}$ \\ 'Diabetic Foot Section, Pisa University \\ Hospital, Pisa, Italy; ${ }^{2}$ Dermatology \\ Department, Pisa University Hospital, \\ Pisa, Italy; ${ }^{3}$ Bariatric Surgery Unit, Pisa \\ University Hospital, Pisa, Italy
}

\begin{abstract}
Aim: To evaluate the distinct contribution of obesity and diabetes (DM) to the skin modification in metabolic diseases.

Methods: We analysed all patients admitted for bariatric surgery in our hospital with BMI between 38 and $47 \mathrm{~kg} / \mathrm{m}^{2}$, with (Group 1) or without (Group 2) DM and compared them with a group of nonobese diabetic patients (Group 3) and healthy volunteers (Group 4). The following features were evaluated: hardness, temperature, hydration and thickness alongside with anthropometric measures of foot and leg.

Results: For the general characteristics, patients differed in age and body mass index. As predictable all circumferences (dorsal foot, sovramalleolar and under the knee) were significantly higher in obese with no differences depending on DM (all parameters: $\mathrm{p}<0.01$ in Group 1 and Group 2 vs Group 3 and Group 4). Skin temperature was significantly higher in all obese, irrespectively from the presence of DM (1st metatarsal head: $\mathrm{p}=0.02$ Group 1 and Group 2 vs Group 3 and Group 4; 5th metatarsal head: $\mathrm{p}<0.01$ in Group 1 and Group 2 vs Group 3 and Group 4). Skin hydration score showed increased anhydrosis in both diabetics and severe obesity $(p<0.01$ in Group 1 and Group 3 vs Group 2 and Group 4). Increase in thickness of skin and subcutaneous tissues was observed (at heel: $\mathrm{p}<0.01$ in Group 1 and Group 2 vs Group 3 and Group 4 and under the scaphoid $\mathrm{p}=0.03$ Group 1 and Group 2 vs Group 3 and Group 4) and plantar fascia (in both regions p=0.02 Group 1 and Group 2 vs Group 3 and Group 4) in all obese patients, with or without DM.

Conclusion: Severe obesity significantly affects both shape and structure of the foot, possibly exposing these patients to a higher risk of biomechanical stress. On such a background DM, modifying skin hydration and protective mechanisms exerts a synergistic role further increasing the risk of trauma and ulcers.
\end{abstract}

Keywords: diabetes, obesity, skin disease

\section{Introduction}

Diabetes mellitus and obesity represent paradigmatic examples of systemic multifactorial chronic diseases, whose clinical characteristics lead to skin disturbances, which are often dependent on overlapping pathogenic mechanisms. ${ }^{1}$

In both pathologies, the cutaneous system undergoes progressive changes, which are closely related to the severity and duration of the underlying chronic diseases. ${ }^{2}$

Chronic hyperglycemia, through many pathogenic pathways, determines the development of systemic chronic complications that affect many systems and organs. ${ }^{3}$ The skin, which is the largest organ in the body, is also a target for complications. ${ }^{4}$ The non-enzymatic glycosylation of skin proteins, with the production of advanced
Correspondence: Marco Romanelli Dermatology Unit, Via Roma, 67, Pisa 56126, Italy

Tel +39050992436

$\mathrm{Fax}+39050551124$

Email m.romanelli@med.unipi.it 
glycosylation end products (AGEs), induces an increased production of reactive oxygen species (ROS) and possible disturbances in the balance of nitric oxide (NO). ${ }^{5}$ These same mechanisms are involved in determining skin complications, in particular increased levels of AGEs seem to play a crucial role. ${ }^{6}$ In fact when structural skin proteins, such as collagen, undergo glycosylation, they lose their elasticity and become insoluble and resistant to degradation and turnover. At the same time polyneuropathy and macroangiopathy also exert their effects on the skin. ${ }^{7}$ Neuropathy leads to a reduction in sensitive innervation, which is present for an initial period of years after a diagnosis of diabetes. ${ }^{8}$ Microvessels show homogeneous thickening of the basement membrane and of the walls of small-caliber vessels together with increased space between endothelial cells and pericytes in post-capillary veins. ${ }^{9}$ The impact on skin function is the consequence of this structural modification such as increased capillary permeability and basal pressure values with chronic interstitial oedema. $^{10}$

Obesity is characterized by insulin resistance and compensatory hyperinsulinemia, ${ }^{11}$ which in turn lead to changes in the structure and morphology of the skin. ${ }^{12}$ The first detectable shift is the loss of function of the skin barrier with an increase in trans-epidermal water loss. ${ }^{13}$ At the microcirculatory level, an increase in cutaneous blood flow has been described both in basal and peak values together with a compensatory reduction in the mean flow velocity. ${ }^{14}$ These changes appear to be related to changes in parasympathetic nerve activity, ${ }^{15}$ while the sympathetic branch is constitutively activated with a chronic increase in sweat gland secretion, especially at the palmar surface of the hands and plantar region of the feet. ${ }^{16}$ The clinical result consists of both skin diseases that are common to non-obese subjects and which are generally exacerbated by the overlap of obesity, and by diseases more closely related to the pathophysiological picture of obesity and insulin resistance. ${ }^{17}$

\section{Materials and Methods}

The aims of our study were to evaluate the impact of diabetes mellitus and obesity on skin and subcutaneous tissues. In particular, we can identify:

Primary outcome: to explore the changes induced by diabetes mellitus and obesity on the cutaneous and subcutaneous lower limb system.

Secondary outcome: to evaluate the impact on the differences observed among groups of, respectively, diabetes and obesity.

\section{Patients and Methods}

Patients scheduled for bariatric surgery with or without diabetes mellitus were recruited from the Bariatric Surgery Department of our hospital and nonobese diabetic patients were recruited from the Diabetology Department. Healthy volunteers were also recruited as a control group.

The following inclusion criteria were considered: age, between 18 and 65 years, diabetes duration $>5$ yrs, release of informed consent, compliance with study procedures and ability to walk without aids. Exclusion criteria were: active ulceration or history of foot ulcer or foot and leg surgery, Charcot neuro-osteoarthropathy, presence of peripheral arterial disease or severe diabetic retinopathy, active neoplasms, other skin diseases that might interfere with the study, inability to give consent, and life expectancy shorter than 1 year.

In accordance with the body mass index and the presence or absence of diabetes, patients were divided into four groups as reported in Table 1.

\section{Study Procedures}

After approval by the ethics committee of Pisa University Hospital and the release of the written informed consent, all the patients included in the study underwent a complete physical examination, measurement of anthropometric parameters, a cutaneous physical examination and ultrasound foot assessment. All measurements were taken of both the right (R) and left (L) foot and leg, and were analyzed separately. Measurements were performed after 15 mins of acclimatization in a consultation room where temperature and relative humidity were adjusted to $21 \pm 1^{\circ}$ $\mathrm{C}$ and $50 \pm 3 \%$, respectively. Figure 1 illustrates the practical execution of the various assessments.

The study was conducted in accordance with Good clinical practice and Helsinki declaration principles.

\section{Physical Complete Examination}

The complete clinical history of each patient was analysed both systemically and focused on lower limbs. Patients were also submitted to a complete objective examination. Arterial

Table I Group Distribution According to Body Mass Index (BMI) and Presence of Diabetes

\begin{tabular}{|l|l|l|}
\hline Group & Diabetes & Obesity (Body Mass Index) \\
\hline $\mathrm{I}$ & Yes $(>5 \mathrm{yrs})$ & Yes $\left(38-47 \mathrm{Kg} / \mathrm{m}^{2}\right)$ \\
2 & No & Yes $\left(38-47 \mathrm{Kg} / \mathrm{m}^{2}\right)$ \\
3 & Yes $(>5 \mathrm{yrs})$ & No $\left(<26 \mathrm{Kg} / \mathrm{m}^{2}\right)$ \\
4 & No & No $\left(<26 \mathrm{Kg} / \mathrm{m}^{2}\right)$ \\
\hline
\end{tabular}




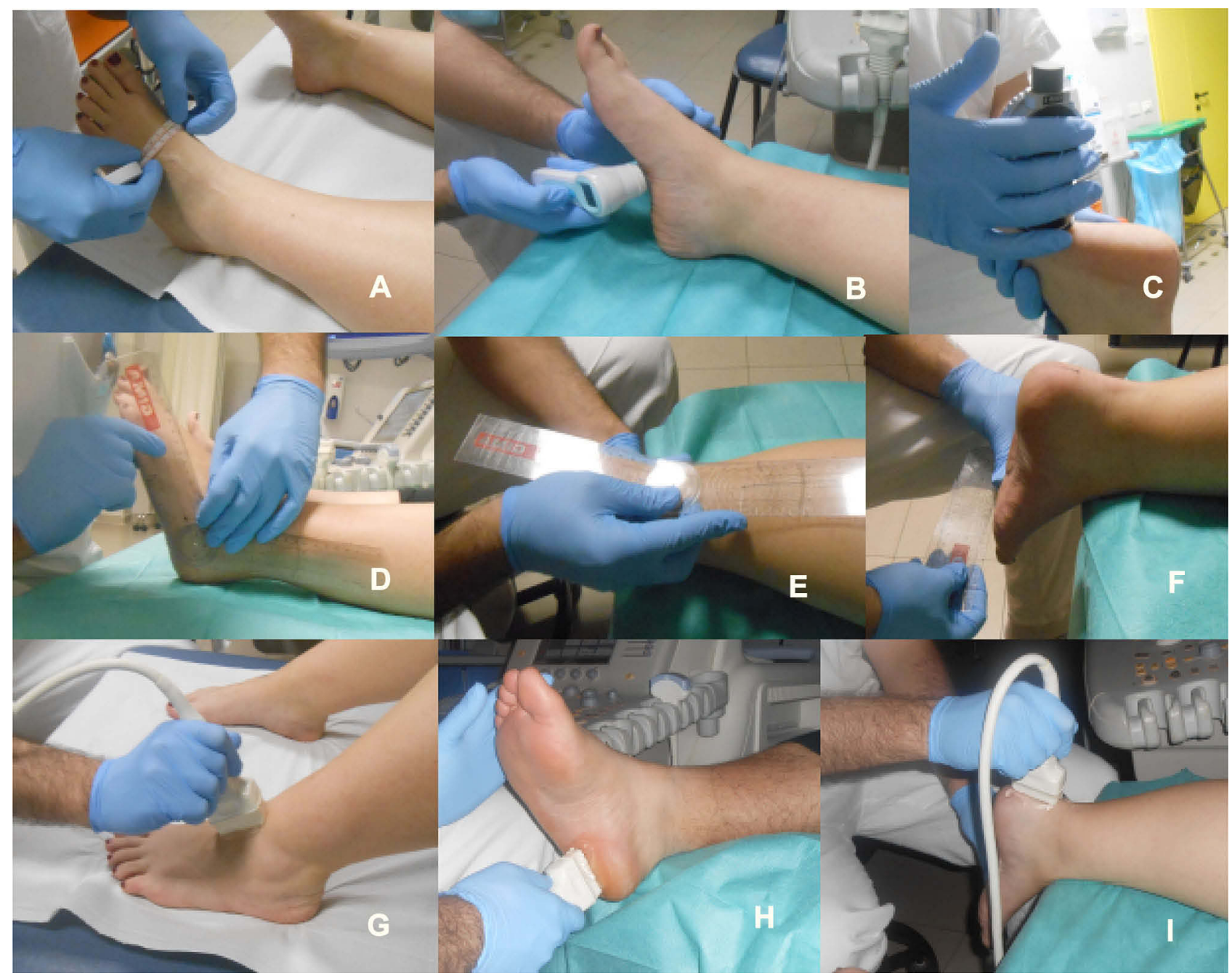

Figure I Practical assessment of anthropometric parameters (A), skin temperature (B), skin hardness (C), osteoarticular parameters (D-F) and ultrasound analysis at dorsum of the foot $(\mathbf{G})$, at plantar surface $(\mathbf{H})$ and Achilles tendon $(\mathbf{I})$.

blood pressure and heart rate, both supine and upright were recorded. Arterial blood pressure was measured first supine, after 10 mins of rest with eyes closed in a dark and silent environment, by an aneroid sphygmomanometer. After the first measurement, the patient was positioned upright and the pressure measurement was repeated, within 2 mins of standing. The results were the mean of three consecutive measurements at a distance of 2 mins from each other, obtained by adding the values together and dividing by three.

\section{Anthropometric Parameters}

We evaluated the circumference of the foot at the dorsal region, over the prominence of the medial cuneiform bone, and the circumference of the leg at the ankle, immediately above the inter-malleolar line and at the calf. The latter measurement was obtained with the patient standing with his/her feet $25 \mathrm{~cm}$ apart in a relaxed position, with the weight evenly distributed on both feet. The tape was positioned around the calf at the widest part, after ensuring that the tape was horizontal around the calf, and by moving it up and down to locate the maximum circumference. The length of the foot was then measured, as the linear distance from the posterior point of the heel to the most anterior point of the longest toe (first or second) measured parallel to the foot axis.

All evaluations were performed using an anthropometric tape on bare skin. The results were the mean of three consecutive measurements, obtained by adding the values and dividing by three.

\section{Cutaneous Physical Examination}

The temperature was measured using an infrared thermometer (Braun - Kromberg - Germany), and hardness was 
measured using a portable shore durometer (O.M.A.G. Varese - Italy). Evaluations were performed in a prone position, after 10 mins of rest, and the instruments were positioned on the plantar surface of the foot at median points of the lines joining the center of the calcaneum with the first and fifth metatarsal-phalangeal joints. Skin hydration was evaluated using a score ranging from 1 to 5 for both feet as previously described (Table $2^{18}$ ). The reported values represent the mean of four different values registered at the plantar surface of the heel, under the scaphoid region and at the 1st and 5th metatarsal heads.

\section{Foot Cutaneous Ultrasound Evaluation}

We measured the thickness of the skin and subcutaneous tissue overall in the dorsal region of the feet at the intersection between the intermalleolar line and the line passing by the first intermetatarsal space. The skin and subcutis on the plantar surface were then measured at the intersection between the longitudinal axis of the calcaneum and the intermalleolar line, at the first and fifth metatarsal head and at the level of the plantar arch above the scaphoid. The thickness of the plantar fascia was also measured at the intersection between the longitudinal axis of the calcaneum and the intermalleolar line and at the level of the plantar arch above the scaphoid together with the thickness of the Achilles tendon at the posterodorsal tuberculum of the calcaneum (Figure 2).

The analysis was performed by a Logiq 7pro ultrasound system (GE Healthcare Medial systems - Chicago, Illinois - USA) using a $12 \mathrm{Mhz}$ linear probe.

Table 2 Skin Hydration Score ${ }^{18}$

\begin{tabular}{|l|l|l|}
\hline Score & Definition & Characteristics \\
\hline I & Anhydrosis & $\begin{array}{l}\text { Absent sweating, fissuration, } \\
\text { desquamation, anelastic skin, absent } \\
\text { pliability. }\end{array}$ \\
\hline 2 & Hypohidrosis & $\begin{array}{l}\text { Sweating present only after stimulation, } \\
\text { reduction or absence of } \\
\text { dermatoglyphics, low pliability }\end{array}$ \\
\hline 3 & Normohydration & $\begin{array}{l}\text { Spontaneous sweating, normal pliability } \\
\text { and glyph, skin normoelastic }\end{array}$ \\
\hline 4 & Hyperhydrosis & $\begin{array}{l}\text { Excessive sweating after stimulation, } \\
\text { hypertrophic dermatoglyphics, sporadic } \\
\text { maceration in the interdigital areas }\end{array}$ \\
\hline 5 & Maceration & $\begin{array}{l}\text { Spontaneous excessive sweating, diffuse } \\
\text { maceration, wet skin, eventual eczema }\end{array}$ \\
\hline
\end{tabular}

\section{Statistical Analysis}

Quantitative variables were expressed as mean, median, and standard deviation, and qualitative variables as frequencies and percentages. Data were compared with the Chi-square and Fisher's exact tests for the categorical data, and with the Student's $t$-test for the continuous variables. The statistical analysis was performed with SAS software (SAS Institute, Cary, NC). A p value of less than 0.05 was considered statistically significant.

\section{Results}

From March to October 2018, we enrolled 120 patients who respected all our inclusion and exclusion criteria. Details of the enrolled population are reported in Figure 3. Table 3 reports the main clinical and demographic characteristics.

In terms of the general characteristics, patients differed in age (Group 3 vs Group 4, p<0.01) and body mass index $(\mathrm{p}<0.01$ Group 1 vs Group 3 and Group 4; Group 2 vs Group 3 and Group 4), as expected in accordance with the study design. Among diabetic patients, we observed no differences in terms of duration of disease or glycemic control. The assessment of vital parameters did not show differences in terms of blood pressure or heart rate between the groups irrespective of the presence or absence of diabetic patients. Both obese and nonobese patients showed a significantly higher difference in systolic pressure from lying to standing position ( $\mathrm{p}<0.01$ in Group 1 vs Group 2 and Group 4; Group 3 vs Group 2 and Group 4) and heart rate increase ( $\mathrm{p}=0.02$ Group 3 vs Group 2 and Group 4 and $p<0.01$ in Group 1 vs Group 2 and Group 4).

No differences were observed regarding trauma history at the lower limbs or regarding skin or rheumatological diseases. No signs of lower limb vascular disease were detected, in particular all patients applicant for bariatric surgery underwent venous ultrasound analysis, negative for venous incontinence. All other patients did not present clinical signs of venous damage.

No differences were observed in all parameters among the sides of measurement. The results above were confirmed both in the right and left foot and leg.

\section{Anthropometric Parameters}

As expected, all circumferences were significantly higher in the obese groups, with no differences whether they were diabetic or not (for all parameters: $\mathrm{p}<0.01$ in Group 1 vs Group 3 and Group 4; Group 2 vs Group 3 and Group 4). No differences were observed regarding foot length. Details are reported in Table 4. 


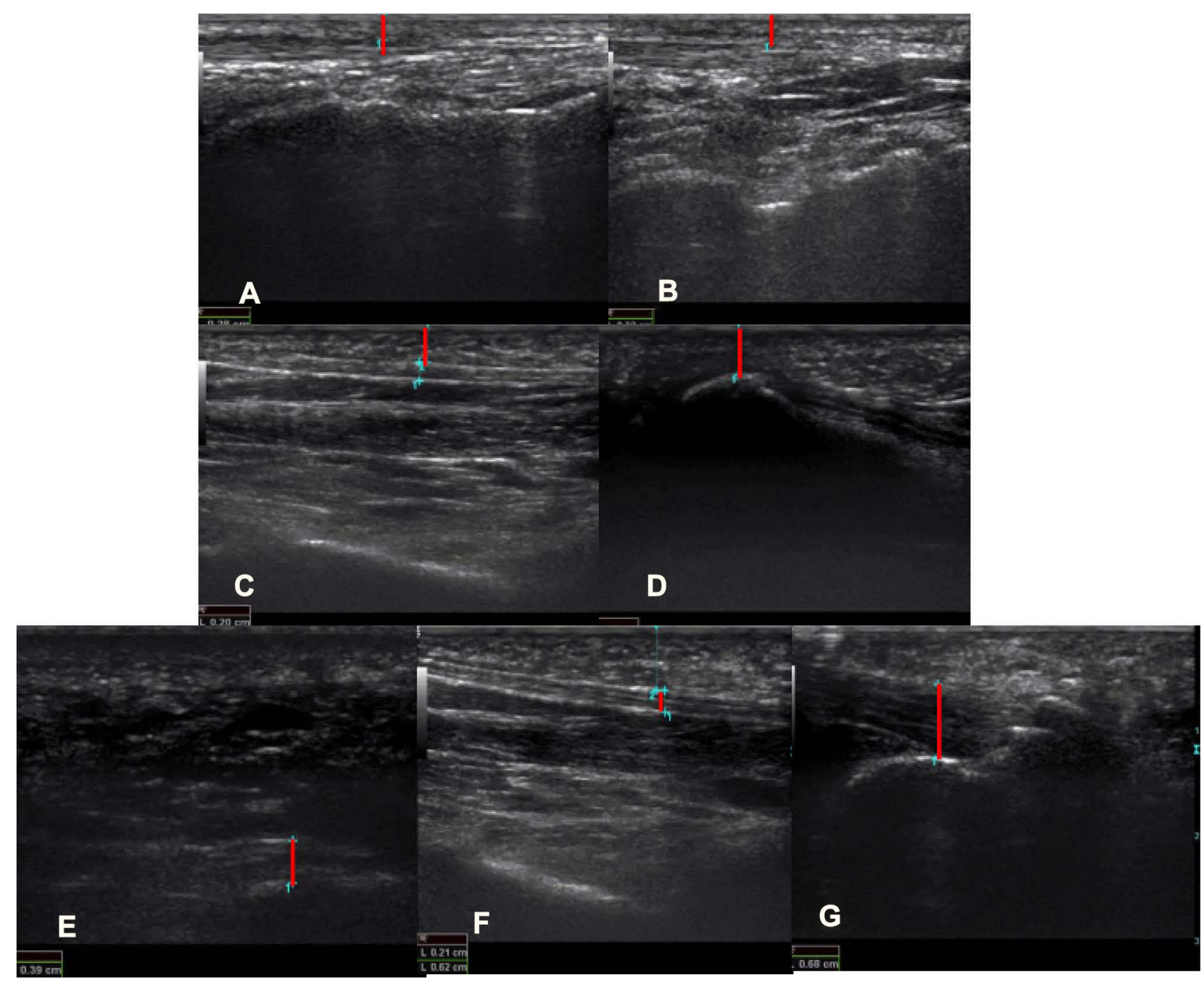

Figure 2 Measurement of skin and subcutaneous tissue in dorsal foot region $(\mathbf{A})$, heel region (B), under the scaphoid $(\mathbf{C})$ and under the metatarsal heads $(\mathbf{D})$; measurement of plantar fascia at heel $(\mathbf{E})$ and under the scaphoid $(\mathbf{F})$; measurement of Achilles tendon at its insertion $(\mathbf{G})$.

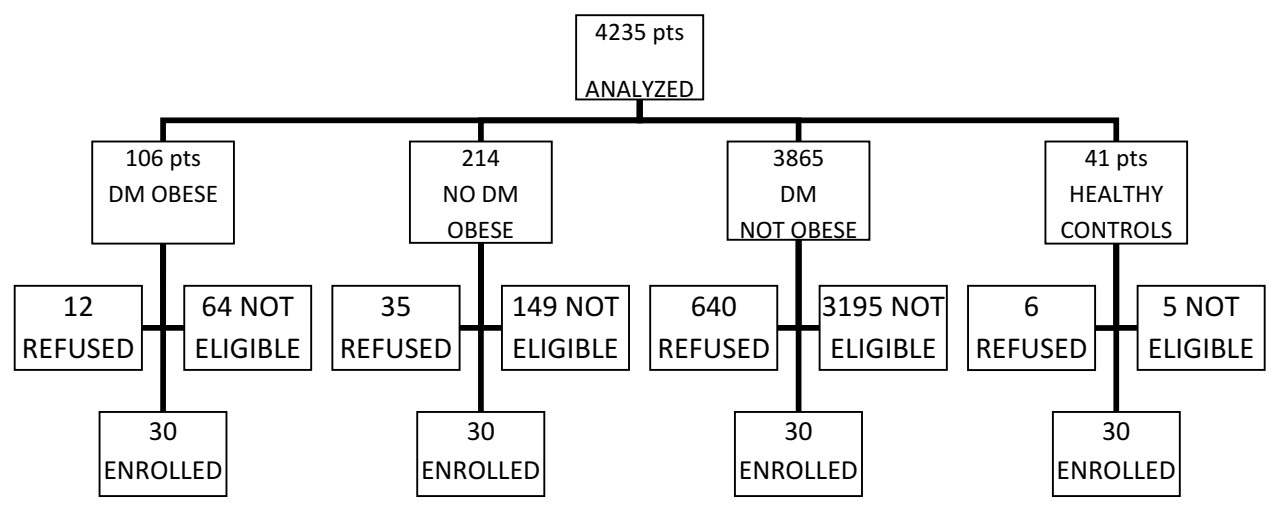

Figure 3 Consort diagram of the study population.

\section{Cutaneous Physical Examination}

No differences were observed between the groups regarding skin hardness, while skin temperature was significantly higher in all obese patients, irrespective of the presence of diabetes (1st metatarsal head, right foot: $\mathrm{p}=0.02$ Group 1 vs Group 3 and Group 4 and Group 2 vs Group 3 and 
Table 3 Group Distribution, Clinical Characteristics and Vital Parameters

\begin{tabular}{|c|c|c|c|c|c|}
\hline Characteristic & Group I & Group 2 & Group 3 & Group 4 & $\mathbf{p}$ \\
\hline Diabetes & Yes & No & Yes & No & \\
\hline Obesity & Yes & Yes & No & No & \\
\hline Number of patients & 30 & 30 & 30 & 30 & - \\
\hline Mean age (yrs) & $45.0 \pm 6.8$ & $47.3 \pm 8.3$ & $51.0 \pm 4.5$ & $36.5 \pm 8.4$ & $0.01^{\circ}$ \\
\hline BMI $\left(\mathrm{Kg} / \mathrm{m}^{2}\right)$ & $42.9 \pm 4.5$ & $41.2 \pm 5.4$ & $24.9 \pm 2.2$ & $23.5 \pm 1.5$ & $0.0 I^{*}$ \\
\hline Duration of diabetes (yrs) & $7 \pm 1$ & - & $8 \pm 2$ & - & - \\
\hline $\mathrm{HbAlc}(\%)$ & $7.1 \pm 1.8$ & - & $7.2 \pm 2.0$ & - & - \\
\hline SBP supine & $|4| \pm 23$ & $134 \pm 17$ & $129 \pm 29$ & $130 \pm 19$ & ns \\
\hline DBP supine & $77 \pm 5$ & $78 \pm 3$ & $78 \pm 4$ & $76 \pm 5$ & ns \\
\hline SBP upright & $119 \pm 20$ & $125 \pm 19$ & $118 \pm 17$ & $129 \pm 17$ & ns \\
\hline DBP upright & $74 \pm 9$ & $75 \pm 7$ & $73 \pm 10$ & $76 \pm 9$ & ns \\
\hline Delta SBP & $23 \pm 5$ & $6 \pm 4$ & $18 \pm 8$ & $3 \pm 2$ & $0.01^{\#}$ \\
\hline Heart rate supine & $65 \pm 11$ & $67 \pm 9$ & $62 \pm 14$ & $74 \pm 8$ & ns \\
\hline Heart rate upright & $74 \pm 10$ & $70 \pm 11$ & $77 \pm 8$ & $76 \pm 9$ & ns \\
\hline Delta heart rate & $9 \pm 6$ & $3 \pm 2$ & $11 \pm 5$ & $2 \pm 1$ & $0.02^{\S}$ \\
\hline
\end{tabular}

Notes: ${ }^{\circ}$ Group 3 vs Group I, Group 2 and Group 3 and Group 4 vs Group I and Group 2. *Group I vs Group 3, Group 4 and Group 2 vs Group 3 and Group 4. ${ }^{\#}$ Group I vs Group 2 and Group 4 and Group 3 vs Group 2 and Group $4 .{ }^{\S}$ Group 3 vs Group 2 and Group 4 and p<0.0I in Group I vs Group 2. Abbreviations: BMI, body mass index; SBP, systolic blood pressure; DBP, diastolic blood pressure.

Table 4 Differences in Anthropometric Characteristics

\begin{tabular}{|l|l|l|l|l|l|}
\hline Circumference (cm) & Group I & Group 2 & Group 3 & Group 4 & P \\
\hline Diabetes & Yes & No & Yes & No & \\
Obesity & Yes & Yes & No & No & \\
Dorsal foot (R) & $25.5 \pm 3.6$ & $26.2 \pm 1.4$ & $20.8 \pm 1.4$ & $21.1 \pm 1.3$ & $0.01^{\circ}$ \\
Dorsal foot (L) & $26.1 \pm 3.8$ & $25.6 \pm 1.8$ & $20.6 \pm 1.4$ & $19.9 \pm 1.2$ & $0.01^{\circ}$ \\
Overmalleolar leg (R) & $28.2 \pm 2.9$ & $27.6 \pm 1.0$ & $20.9 \pm 1.6$ & $20.5 \pm 1.2$ & $0.01^{\circ}$ \\
Overmalleolar leg (L) & $26.8 \pm 3.1$ & $27.3 \pm 1.4$ & $21.1 \pm 1.4$ & $21.4 \pm 1.1^{\prime}$ & $0.01^{\circ}$ \\
Below-knee leg (R) & $44.5 \pm 4.6$ & $43.1 \pm 3.0$ & $32.6 \pm 3.1$ & $33.8 \pm 3.9$ & $0.01^{\circ}$ \\
Below-knee leg (L) & $44.1 \pm 3.4$ & $43.5 \pm 1.3$ & $33.6 \pm 1.1$ & $31.9 \pm 1.5$ & $0.01^{\circ}$ \\
Length of foot (R) & $28.5 \pm 2.3$ & $28.2 \pm 2.0$ & $28.0 \pm 2.6$ & $28.4 \pm 2.9$ & $\mathrm{~ns}$ \\
Length of foot (L) & $28.4 \pm 2.2$ & $28.0 \pm 2.8$ & $28.1 \pm 2.0$ & $29 \pm 1.8$ & $\mathrm{~ns}$ \\
\hline
\end{tabular}

Note: ${ }^{\circ}$ Group 1 vs Group 3 and Group 4; Group 2 vs Group 3 and Group 4.

Group 4 - 1st metatarsal head, left foot: $\mathrm{p}=0.02$ Group 1 vs Group 3 and Group 4 and Group 2 vs Group 3 and Group 4 - 5th metatarsal head, right foot: $\mathrm{p}<0.01$ Group 1 vs Group 3 and Group 4 and Group 2 vs Group 3 and Group 4 - 5th metatarsal head, right foot: $\mathrm{p}<0.01$ Group 1 vs Group 3 and Group 4 and Group 2 vs Group 3 and Group 4). Low scores in the skin hydration score indicated increased levels of anhydrosis in diabetic patients. However, unlike other parameters, diabetes exerted a synergistic effect when associated with obesity (Right foot: $\mathrm{p}<0.01$ Group 1 vs Group 3 and Group 4 and Group 2 vs Group 1 and Group 4 - Left foot: $\mathrm{p}<0.01$ Group 1 vs Group 3 and Group 4 and Group 2 vs Group 1 and Group 4). Data are detailed in Table 5.

\section{Foot Cutaneous Ultrasound Evaluation}

Ultrasound revealed an increase in the thickness of skin and subcutaneous tissues and plantar fascia in the heel region and under the scaphoid in all obese patients, irrespectively of the presence of diabetes. Both thickness of cutis and subcutaneous tissue were more important in obese patients at the heel region in the right $(p<0.01$ Group 1 vs Group 3 and Group 4 and Group 2 vs Group 3 and Group 4) and left foot ( $<<0.01$ Group 1 vs Group 3 and Group 4 and Group 2 vs Group 3 and Group 4) and under the scaphoid in the right $(\mathrm{p}=0.03$ Group 1 vs Group 3 and Group 4 and Group 2 vs Group 3 and Group 4) and left foot ( $\mathrm{p}=0.03$ Group 1 vs Group 3 and Group 4 and Group 2 vs Group 3 and Group 4). 
Table 5 Skin Evaluation in Groups

\begin{tabular}{|l|l|l|l|l|l|}
\hline Parameter & Group I & Group 2 & Group 3 & Group 4 \\
\hline Diabetes & Yes & No & Yes & No \\
Obesity & Yes & Yes & No & No \\
Temperature I mts R & $31.3 \pm 4.7$ & $33.9 \pm 3.8$ & $28.2 \pm 3.8$ & $28.4 \pm 3.5$ & $27.3 \pm 2.4$ \\
Temperature I mts L & $31.3 \pm 4.5$ & $33.8 \pm 3.9$ & $27.9 \pm 2.9$ & $27.0 \pm 3.0$ & $0.02^{\circ}$ \\
Temperature V mts R & $30.3 \pm 4.9$ & $33.1 \pm 4.8$ & $27.3 \pm 3.5$ & $0.02^{\circ}$ \\
Temperature V mts L & $30.9 \pm 4.8$ & $34.0 \pm 4.0$ & $27.0 \pm 2.0$ & $0.0 I^{*}$ \\
Hardness I mts R & $19.9 \pm 4.7$ & $20.3 \pm 5.3$ & $19.8 \pm 4.6$ & $19.0 \pm 2.5$ & $0.0 I^{*}$ \\
Hardness I mts L & $20.0 \pm 3.6$ & $20.9 \pm 3.5$ & $19.5 \pm 3.6$ & $18.8 \pm 3.8$ & n.s. \\
Hardness V mts R & $29.9 \pm 6.6$ & $30.1 \pm 6.6$ & $29.5 \pm 7.5$ & $29.2 \pm 7.0$ \\
Hardness V mts L & $29.4 \pm 6.9$ & $28.7 \pm 6.7$ & $30.1 \pm 8.1$ & $30.5 \pm 7.6$ \\
Skin hydration score R & $1.1 \pm 0.4$ & $2.0 \pm 0.5$ & $2.1 \pm 0.6$ & $2.6 \pm 0.5$ \\
Skin hydration score L & $1.3 \pm 0.2$ & $1.9 \pm 0.5$ & $2.0 \pm 0.6$ & $2.4 \pm 0.5$ \\
\hline
\end{tabular}

Notes: ${ }^{\circ}$ Group I vs Group 3 and Group 4; Group 2 vs Group 3 and Group 4. *Group I vs Group 3 and Group 4; Group 2 vs Group 3 and Group $4 .{ }^{\#}$ Group 2 and Group 3 and Group I and Group 4.

Abbreviations: R, right; L, left; mts, metatarsal.

Plantar fascia presented a similar pattern: it was thicker both at the heel in the right ( $\mathrm{p}=0.02$ Group 1 vs Group 3 and Group 4 and Group 2 vs Group 3 and Group 4) and left foot ( $\mathrm{p}=0.02$ Group 1 vs Group 3 and Group 4 and Group 2 vs Group 3 and Group 4) and, again, under scaphoid in the right ( $=0.02$ Group 1 vs Group 3 and Group 4 and Group 2 vs Group 3 and Group 4) and left foot ( $\mathrm{p}=0.02$ Group 1 vs Group 3 and Group 4 and Group 2 vs Group 3 and Group 4).

No differences associated with diabetes were reported between obese or not obese patients. Further details are reported in Table 6.

The impact of, respectively, diabetes and obesity was explored with Cox regression analysis (Table 7) that confirmed the influence of obesity and not of diabetes on anthropometric parameters, skin temperature and ultrasound analysis. Skin hydration was instead determined by both diabetes and obesity that acts together on this value.

\section{Discussion}

Diabetes and obesity are among the most frequent comorbid chronic pathologies affecting millions of patients worldwide, such that the term "diabesity" has been created. ${ }^{19}$ Both pathologies are known to affect skin and musculoskeletal structures (MSS) by means of a variety of mechanisms. ${ }^{20}$ In our study, we evaluated four aspects of skin and MSS affected by obesity and diabetes: thickness, hydration, temperature and hardness, all related to the functional status of the foot (Table 8).

It is well known that obesity leads to musculoskeletal alterations in the feet and legs. Long-term exposure to an increased load on the feet leads to changes in the architecture and mechanical properties of the plantar fascia and heel pad. ${ }^{21}$ These modifications decrease the protective and supportive capacity of the plantar foot region, thus causing foot disorders. ${ }^{22}$

Despite a number of studies investigating the role of plantar fascia in obese subjects in the literature, our study is the first to try to ascertain the role of diabetes in such a context and to differentiate the impacts of the two concomitant pathologies. Our data showed an increase both in plantar fascia, in the skin and subcutaneous tissue in severely obese patients compared to diabetic nonobese subjects and among obese subjects irrespectively of the presence of diabetes. The increase in plantar fascia thickness associated with severe obesity can be interpreted as a compensatory reaction for the elongation and deformation associated with increased loading and not solved by the reduction in plantar stiffness. ${ }^{23}$ On the other hand, in diabetics, an increased thickness of the tendons and plantar structures was found, related to the increase in proteins of the cutaneous structures. ${ }^{24}$ The complete absence of venous disease allowed us to exclude the impact of subcutaneous oedema in clinical findings. Our findings do not confirm the association between those two separate mechanisms in obese patients, in whom the mechanical components seem to play a major role.

The analysis of skin temperature showed an increase in all sites in all obese patients, irrespectively of the presence of diabetes. However, increased temperature today tends to be attributed to the inflammatory changes that precede the onset of an ulcer. ${ }^{25,26}$ 
Table 6 Differences in Ultrasound Evaluation Reported Refer to Obese vs Not Obese Patients

\begin{tabular}{|c|c|c|c|c|c|}
\hline Region (mm) & Group I & Group 2 & Group 3 & Group 4 & $\mathbf{p}$ \\
\hline Diabetes & Yes & No & Yes & No & \\
\hline Obesity & Yes & Yes & No & No & \\
\hline \multicolumn{6}{|l|}{ Skin } \\
\hline Dorsal R & $0.33 \pm 0.08$ & $0.32 \pm 0.08$ & $0.29 \pm 0.07$ & $0.29 \pm 0.08$ & n.s. \\
\hline Dorsal L & $0.35 \pm 0.08$ & $0.34 \pm 0.10$ & $0.34 \pm 0.03$ & $0.29 \pm 0.04$ & n.s. \\
\hline Heel plantar R & $1.42 \pm 0.25$ & $1.39 \pm 0.24$ & $1.12 \pm 0.18$ & $1.14 \pm 0.22$ & $<0.01^{\circ}$ \\
\hline Heel plantar L & $1.35 \pm 0.29$ & $1.40 \pm 0.29$ & $1.15 \pm 0.20$ & $1.11 \pm 0.23$ & $<0.01^{\circ}$ \\
\hline Scaphoid plantar R & $0.68 \pm 0.20$ & $0.67 \pm 0.25$ & $0.60 \pm 0.14$ & $0.63 \pm 0.15$ & $0.03^{*}$ \\
\hline Scaphoid plantar L & $0.69 \pm 0.21$ & $0.65 \pm 0.28$ & $0.59 \pm 0.10$ & $0.57 \pm 0.12$ & $0.03^{*}$ \\
\hline I mts plantar R & $0.55 \pm 0.13$ & $0.53 \pm 0.16$ & $0.44 \pm 0.10$ & $0.4 I \pm 0.06$ & n.s. \\
\hline I mts plantar L & $0.52 \pm 0.13$ & $0.51 \pm 0.13$ & $0.39 \pm 0.08$ & $0.46 \pm 0.11$ & n.s. \\
\hline$V$ mts plantar $R$ & $0.70 \pm 0.15$ & $0.67 \pm 0.18$ & $0.65 \pm 0.07$ & $0.67 \pm 0.12$ & n.s. \\
\hline $\mathrm{V}$ mts plantar $\mathrm{L}$ & $0.66 \pm 0.17$ & $0.68 \pm 0.17$ & $0.62 \pm 0.13$ & $0.64 \pm 0.11$ & n.s. \\
\hline \multicolumn{6}{|l|}{ Plantar Fascia } \\
\hline Heel plantar fascia $R$ & $0.34 \pm 0.07$ & $0.32 \pm 0.09$ & $0.26 \pm 0.05$ & $0.28 \pm 0.06$ & $0.02^{\#}$ \\
\hline Heel plantar fascia $L$ & $0.34 \pm 0.10$ & $0.35 \pm 0.13$ & $0.28 \pm 0.03$ & $0.27 \pm 0.05$ & $0.02^{\#}$ \\
\hline Scaphoid plant fascia $R$ & $0.18 \pm 0.04$ & $0.17 \pm 0.02$ & $0.13 \pm 0.03$ & $0.13 \pm 0.04$ & $0.02^{\#}$ \\
\hline Scaphoid plant fascia $L$ & $0.20 \pm 0.05$ & $0.19 \pm 0.05$ & $0.15 \pm 0.06$ & $0.14 \pm 0.04$ & $0.02^{\#}$ \\
\hline \multicolumn{6}{|l|}{ Achilles Tendon } \\
\hline Achilles tendon $\mathrm{R}$ & $0.48 \pm 0.09$ & $0.47 \pm 0.11$ & $0.4 I \pm 0.02$ & $0.44 \pm 0.03$ & n.s. \\
\hline Achilles tendon L & $0.48 \pm 0.10$ & $0.46 \pm 0.12$ & $0.42 \pm 0.05$ & $0.44 \pm 0.06$ & n.s. \\
\hline
\end{tabular}

Notes: ${ }^{\circ}$ Group I vs Group 3 and Group 4; Group 2 vs Group 3 and Group 4. *Group I vs Group 3 and Group 4; Group 2 vs Group 3 and Group 4 . "Group I vs Group 3 and Group 4; Group 2 vs Group 3 and Group 4.

Abbreviations: $R$, right; $L$, left; $m t s$, metatarsal.

Skin hydration is an important feature of normal skin, since it provides a sufficient degree of elasticity to prevent fissurations. ${ }^{27}$ Both diabetes and obesity have been associated with a modification in skin hydration: diabetes with hypohidrosis because of the sympathetic denervation of sweat glands in the lower extremity, and obesity with hyperhidrosis due to the chronic systemic activation of sympathetic components of the autonomic nervous system. ${ }^{28}$

In chronic phases, in patients at low risk of ulceration, the increase in skin temperature reflects the hemodynamic changes that are typical of obese patients at the microcirculatory level. ${ }^{29}$

We measured the skin hydration score in our patients, which demonstrated normal hydration in the controls, moderate hypohidrosis in nonobese diabetic patients and obese nondiabetic patients, and severe hypohidrosis in obese diabetic patients, suggesting that diabetes exerts a synergistic effect when associated with obesity. To our knowledge, few analyses of skin hydration scores have been performed to date and this is the first time in which the two diseases have been compared. The main limitation of this analysis is represented by the differences in mean age among groups, nevertheless the strength of this association is quite controversial in scientific literature. ${ }^{30}$ On the other hand, while mean age was higher in not obese diabetic patients, the skin hydration is significantly lower in diabetic obese patients, further confirming the synergistic role exerted by the two diseases. The study result was an unexpected finding, since we would expect compensatory hyperhidrosis in obese patients. This could be the effect of the downregulation of sweat in the lower limbs secondary to hyper-sweating in the trunk, however this needs confirming.

We are aware of the limitations of our study, which is single-center based, and possibly biased by the selection of patients, who were mostly referred by other centers to ours both for diabetes care and especially for bariatric surgery.

\section{Conclusions}

Our study has demonstrated how obesity takes the lead in determining morphostructural changes in skin and 
Table 7 Cox Regression Model for Anthropometric Parameters, Skin Temperature, Skin Hydration and Ultrasound Analysis

\begin{tabular}{|c|c|c|c|c|}
\hline Characteristics & $\begin{array}{l}\text { Univariate (HR - } 95 \% \mathrm{Cl}) \\
(\mathrm{HR}-95 \% \mathrm{Cl})\end{array}$ & $\mathbf{p}$ & $\begin{array}{l}\text { Multivariate (HR - 95\% Cl) } \\
(\mathrm{HR}-95 \% \mathrm{Cl})\end{array}$ & $\mathbf{p}$ \\
\hline \multicolumn{5}{|l|}{ Dorsal Foot Circumference } \\
\hline Diabetes & $1.18(0.76-1.30)$ & 0.43 & & \\
\hline Obesity & $1.35(1.23-1.44)$ & 0.02 & $1.47(1.33-1.66)$ & 0.02 \\
\hline \multicolumn{5}{|l|}{ Overmalleolar Leg Circumference } \\
\hline Diabetes & $1.38(0.60-1.63)$ & 0.38 & & \\
\hline Obesity & $1.27(1.15-1.39)$ & 0.02 & $1.56(1.45-1.80)$ & 0.01 \\
\hline \multicolumn{5}{|l|}{ Underknee Leg Circumference } \\
\hline Diabetes & $1.35(0.87-1.57)$ & 0.36 & & \\
\hline Obesity & $1.21(1.05-1.42)$ & 0.02 & $1.33(1.13-1.56)$ & 0.02 \\
\hline \multicolumn{5}{|l|}{ Skin Temperature - I Metatarsal Head } \\
\hline Diabetes & $0.82(0.38-1.88)$ & 0.70 & & \\
\hline Obesity & $1.42(1.12-1.65)$ & 0.04 & $1.32(1.10-1.44)$ & 0.04 \\
\hline \multicolumn{5}{|l|}{ Skin Temperature - V Metatarsal Head } \\
\hline Diabetes & $1.15(0.69-1.37)$ & 0.31 & & \\
\hline Obesity & $1.37(1.25-1.52)$ & 0.02 & $1.48(1.35-1.60)$ & 0.02 \\
\hline \multicolumn{5}{|l|}{ Skin Hydration } \\
\hline Diabetes & $0.55(0.38-0.76)$ & 0.04 & $0.78(0.45-0.94)$ & 0.02 \\
\hline Obesity & $0.87(0.75-0.96)$ & 0.02 & $0.65(0.35-0.82)$ & 0.04 \\
\hline \multicolumn{5}{|l|}{ Skin Thickness - Heel Region } \\
\hline Diabetes & $0.86(0.56-1.34)$ & 0.46 & & \\
\hline Obesity & $1.37(1.15-1.42)$ & 0.04 & $1.45(1.29-1.67)$ & 0.02 \\
\hline \multicolumn{5}{|l|}{ Skin Thickness - Scaphoid Region } \\
\hline Diabetes & $1.15(0.66-1.45)$ & 0.30 & & \\
\hline Obesity & $1.32(1.12-1.52)$ & 0.04 & $1.60(1.38-1.79)$ & 0.02 \\
\hline \multicolumn{5}{|l|}{ Fascia Thickness - Heel Region } \\
\hline Diabetes & $1.55(0.91-1.77)$ & 0.32 & & \\
\hline Obesity & $1.43(1.23-1.67)$ & 0.04 & $1.33(1.21-1.53)$ & 0.04 \\
\hline \multicolumn{5}{|l|}{ Fascia Thickness - Scaphoid Region } \\
\hline Diabetes & $1.32(0.56-1.78)$ & 0.31 & & \\
\hline Obesity & $1.34(1.12-1.65)$ & 0.04 & $1.45(1.23-1.64)$ & 0.02 \\
\hline
\end{tabular}

Table 8 Summary of the Results of Our Study According to Groups and Parameters: - Neutral Effect, + Mild Increase, ++ Moderate Increase, +++ Severe Increase

\begin{tabular}{|l|l|l|l|l|l|}
\hline $\begin{array}{l}\text { Parameter } \\
(\mathbf{c m})\end{array}$ & $\begin{array}{l}\text { Group } \\
\mathbf{I}\end{array}$ & $\begin{array}{l}\text { Group } \\
\mathbf{2}\end{array}$ & $\begin{array}{l}\text { Group } \\
\mathbf{3}\end{array}$ & $\begin{array}{l}\text { Group } \\
\mathbf{4}\end{array}$ & $\mathbf{p}$ \\
\hline Diabetes & Yes & No & Yes & No & \\
Obesity & Yes & Yes & No & No & \\
Temperature & +++ & ++ & - & - & 0.01 \\
Hardness & + & + & - & - & Ns \\
Hydration & +++ & ++ & ++ & - & 0.01 \\
Thickness & ++ & ++ & - & - & 0.01 \\
\hline
\end{tabular}

MSS and in functional changes in the microcirculatory compartment in the lower limbs of super-obese patients. This is without any significant additive effect of diabetes, which in turn significantly influences the clinical features when hydration is taken into consideration.

We are now planning a follow-up evaluation of the same cohort of patients after bariatric surgery, to test whether recovery from obesity could be associated with a normalization of the structural and morpho-functional parameters. 


\section{Disclosure}

The authors report no conflicts of interest in this work.

\section{References}

1. Lehtinen JM, Niskanen L, Hyvönen K, Siitonen O, Uusitupa M. Nerve function and its determinants in patients with newlydiagnosed type 2 (non-insulin-dependent) diabetes mellitus and in control subjects-a 5-year follow-up. Diabetologia. 1993;36(1):68-72. doi:10.1007/BF00399096

2. Yosipovitch G, DeVore A, Dawn A. Obesity and the skin: skin physiology and skin manifestations of obesity. $J$ Am Acad Dermatol. 2007;56(6):901-916. doi:10.1016/j.jaad.2006.12.004

3. Brownlee M. The pathobiology of diabetic complications: a unifying mechanism. Diabetes. 2005;54(6):1615-1625. doi:10.2337/diabetes. 54.6.1615

4. DeFronzo RA, Ferrannini E, Groop L, et al. Type 2 diabetes mellitus. Nat Rev Dis Primers. 2015;1:15019.

5. Beisswenger PJ, Moore LL, Curphey TJ. Relationship between glycemic control and collagen-linked advanced glycosylation end-products in type 1 diabetes. Diabetes Care. 1993;16:689-694. doi:10.2337/diacare.16.5.689

6. Sell DR, La Polla A, Odetti P. Pentosidine formation in skin correlates with severity of complications in individuals with long-standing IDDM. Diabetes. 1992;41:1286-1292. doi:10.2337/diab.41.10.1286

7. Levy DM, Ternghi G, Gu XH. Immunohistochemical measurement of nerves and neuropeptides in diabetic skin: relationship to tests of neurological function. Diabetologia. 1992;35:889-897. doi:10.1007/ BF00399938

8. Braverman IM, Sibley J, Keh-Yen A. A study of the veil cells around normal, diabetic and aged cutaneous micro-vessels. J Invest Dermatol. 1986;86:57-62. doi:10.1111/1523-1747.ep12283816

9. Khalil H. Diabetes Metab Syndr. 2016;pii: S1871-- 4021(16)30264-8.

10. Bollinger A, Frey J, Jager K. Patterns of diffusion through skin capillaries in patients with longterm diabetes. $N$ Engl $J$ Med. 1982;307:1305-1310. doi:10.1056/NEJM198211183072103

11. Ravussin E, Lillioja S, Knowler WC, et al. Reduced rate of energy expenditure as a risk factor for body-weight gain. $N$ Engl $J$ Med. 1988;318(8):467-472. doi:10.1056/NEJM198802253180802

12. Guh DP, Zhang W, Bansback N, Amarsi Z, Birmingham CL, Anis $\mathrm{AH}$. The incidence of co-morbidities related to obesity and overweight: a systematic review and meta-analysis. BMC Public Health. 2009;25(9):88. doi:10.1186/1471-2458-9-88

13. García Hidalgo L. Dermatological complications of obesity. Am $J$ Clin Dermatol. 2002;3(7):497-506. doi:10.2165/00128071-2002 03070-00006

14. de Jongh RT, Serné EH, IJzerman RG, de Vries G, Stehouwer CD. Impaired microvascular function in obesity: implications for obesity-associated microangiopathy, hypertension, and insulin resistance. Circulation. 2004;109(21):2529-2535. doi:10.1161/01. CIR.0000129772.26647.6F
15. Khan AS, Sane DC, Wannenburg T, Sonntag WE. Growth hormone, insulin-like growth factor-1 and the aging cardiovascular system. Cardiovasc Res. 2002;54(1):25-35. doi:10.1016/S0008-6363(01)00533-8

16. Yosipovitch G, Tur E, Cohen O, Rusecki Y. Skin surface $\mathrm{pH}$ in intertriginous areas in NIDDM patients. Possible Correlation to Candidal Intertrigo. Diabetes Care. 1993;16(4):560-563.

17. Haffner SM. Sex hormones, obesity, fat distribution, type 2 diabetes and insulin resistance: epidemiological and clinical correlation. Int $J$ Obes Relat Metab Disord. 2000;24(Suppl 2):S56-8. doi:10.1038/sj.ijo.0801279

18. Banchellini E, Macchiarini S, Dini V, et al. Use of nanotechnology-designed footsock in the management of preulcerative conditions in the diabetic foot: results of a single, blind randomized study. IJLEW. 2008;2:82-87.

19. Pappachan JM, Viswanath AK. Medical management of diabesity: do we have realistic targets? Curr Diab Rep. 2017;17(1):4. doi:10.1007/ s11892-017-0828-9

20. Eghbalzadeh K, Brixius K, Bloch W, Brinkmann C. Skeletal muscle nitric oxide (NO) synthases and NO-signaling in "diabesity"-what about the relevance of exercise training interventions? Nitric Oxide. 2014;15(37):28-40. doi:10.1016/j.niox.2013.12.009

21. Butterworth PA, Urquhart DM, Landorf KB, Wluka AE, Cicuttini FM, Menz HB. Foot posture, range of motion and plantar pressure characteristics in obese and non-obese individuals. Gait Posture. 2015;41:465-469. doi:10.1016/j.gaitpost.2014.11.010

22. Frey C, Zamora J. The effects of obesity on orthopaedic foot and ankle pathology. Foot Ankle Int. 2007;28:996-999. doi:10.3113/ FAI.2007.0996

23. Sun P-C, Shih S-L, Chen Y-L, Hsu Y-C, Yang R-C, Chen C-S. Biomechanical analysis of foot with different foot arch heights: a finite element analysis. Comput Methods Biomech Biomed Eng. 2012;15(6):563-569. doi:10.1080/10255842.2010.550165

24. Kumar CG, Rajagopal KV, Hande HM, Maiya AG, Mayya SS. Intrinsic foot muscle and plantar tissue changes in type 2 diabetes mellitus. J Diabetes. 2015;7(6):850-857. doi:10.1111/1753-0407.12254

25. Bus SA. Innovations in plantar pressure and foot temperature measurements in diabetes. Diabetes Metab Res Rev. 2016;32(Suppl 1):221-226. doi:10.1002/dmrr.2760

26. Yavuz M, Erdemir A, Botek G, Hirschman GB, Bardsley L, Davis BL. Peak plantar pressure and shear locations: relevance to diabetic patients. Diabetes Care. 2007;30:2643-2645. doi:10.2337/dc07-0862

27. Verdier-Sévrain S, Bonté F. Skin hydration: a review on its molecular mechanisms. J Cosmet Dermatol. 2007;6(2):75-82. doi:10.1111/ jcd.2007.6.issue-2

28. Gandecka A, Araszkiewicz A, Piłaciński S, Wierusz-Wysocka B, Zozulińska-Ziółkiewicz D. Evaluation of sudomotor function in adult patients with long-lasting type 1 diabetes. Pol Arch Intern Med. 2017;127(1):16-24. doi:10.20452/pamw.3884

29. Katić K, Li R, Kingma B, Zeiler W. Modelling hand skin temperature in relation to body composition. J Therm Biol. 2017;69:139-148. doi:10.1016/j.jtherbio.2017.07.003

30. Dąbrowska AK, Spano F, Derler S, Adlhart C, Spencer ND, Rossi RM. The relationship between skin function, barrier properties, and body-dependent factors. Skin Res Technol. 2018;24(2):165-174. doi:10.1111/srt.2018.24.issue-2

Diabetes, Metabolic Syndrome and Obesity: Targets and Therapy

\section{Dovepress}

\section{Publish your work in this journal}

Diabetes, Metabolic Syndrome and Obesity: Targets and Therapy is an international, peer-reviewed open-access journal committed to the rapid publication of the latest laboratory and clinical findings in the fields of diabetes, metabolic syndrome and obesity research. Original research, review, case reports, hypothesis formation, expert opinion and commentaries are all considered for publication. The manuscript management system is completely online and includes a very quick and fair peer-review system, which is all easy to use. Visit http://www.dovepress.com/testimonials.php to read real quotes from published authors. 